Research Paper

\title{
Vitamin D3 Intake Dose and Common Cancer: A Population-Based Case Control Study in a Chinese Population
}

\author{
Henry WC Leung1,2, Chih-Hsin Muo ${ }^{3}$, Chung-Feng Liu ${ }^{4}$, Agnes LF Chan²,5凶 \\ 1. Department of Radiation Therapy, An-Nan Hospital, China Medical University, Tainan, Taiwan; \\ 2. Department of Nursing, Min-Hwei College of Health Care management, Tainan City 736, Taiwan; \\ 3. Management Office for Health Data, China Medical University Hospital, Taichung, Taiwan; \\ 4. Department of Information Management, Chia Nan University of Pharmacy \& Science, Tainan City 71710, Taiwan; \\ 5. Department of Pharmacy, An-Nan Hospital, China Medical University, Tainan, Taiwan. \\ $\square$ Corresponding authors: Agnes LF Chan, No. 66, Sec. 2, Changhe Rd., Annan Dist., Tainan, Taiwan. Tel: +886-6-3553111, e-mail: agnes.lf@ gmail.com. \\ Chung-Feng Liu, No. 60, Sec 1, Erren Rd., Rende Dist, Tainan City 71710, Taiwan. Tel: +886-6-2664911-5301. email: fredliu@mail.cnu.edu.tw.
}

() Ivyspring International Publisher. Reproduction is permitted for personal, noncommercial use, provided that the article is in whole, unmodified, and properly cited. See http://ivyspring.com/terms for terms and conditions.

Received: 2016.06.16; Accepted: 2016.09.18; Published: 2016.10.21

\begin{abstract}
Objectives: Epidemiological studies suggest that vitamin $D$ status is associated inversely with risk of common cancers in western populations. This study aimed to investigate whether vitamin $D$ is associated with risk of common cancers in Chinese population.

Methods: A population-based retrospective case-control study was conducted analyzing data retrieved from the Catastrophic Illness Patient Databases (CIPD) and longitudinal health insurance database (LHID) from January 1, 2010 to December 31, 201 l and January 1, 2000 to December 31, 2011, respectively. Cases were identified as subjects diagnosed with site-specific cancers (International Classification of Diseases, Ninth Revision,) and frequency matched to select controls. Use of vitamin D3 was compared between two groups. Odds ratios (ORs) were employed to quantify the risk associated with exposure to vitamin D3 by logistic regression.

Results: There were $1.21 \%(1961 / 161806)$ patients in cases and $0.67 \%(1092 / 161806)$ patients in controls identified were vitamin D3 users. Overall risk of cancers associated with vitamin D3 users was 1.67 (95\% Cl:1.55-1.81). Among these, the risk of kidney cancer and bladder cancer associated with intakes of vitamin D3 were significant (OR 2.59; 95\% Cl 1.81-3.70; OR 4.97; 95\% $\mathrm{Cl} 4.40-5.60)$ in an adjusted model. In further stratification analysis, we found a statistically significant risk of bladder cancer associated with high intake of vitamin D3. Except this, no statistically significant risk of other site-specific cancers associated with high intake of vitamin D3.

Conclusion: Except bladder cancer in stratification analysis, we observed no statistically significant association between high intake of vitamin D3 and other site-specific cancers.
\end{abstract}

Key words: site-specific cancer, population-based study, vitamin D, odds ratio, incidence.

\section{Introduction}

Cancer is among the cause of morbidity and mortality worldwide and the first leading cause of death in Taiwan in 2012 and 2014 [1,2]. Many risk factors have been known to be an etiology of cancer including ageing, obesity, unhealthy diet, alcohol and tobacco use, infection by HBV and HPV, radiation, air pollution and genes [3]. Vitamin D is a fat-soluble vitamin and can be ingested from diet or dietary supplements. It has many biologic functions including antiproliferative and antiangiogenic effects to modulation of the immune system [4].

The role of vitamin D in protection of cancers remains inconclusive. Some researchers recommended that vitamin D could play an important 
role in some of the common pathways of cancer due to its ability to induce apoptosis and prevent angiogenesis and thus reducing the malignant cell survival [5-7]. The previous observational studies and reviews indicated that higher intake or serum level of 25-hydroxyvitamin D $(25(\mathrm{OH}) \mathrm{D})$ were associated with lower incidence rates of various cancers, such as breast cancer, colorectal, lung cancer, prostate cancer, bladder cancer [8-19]. However, some recent randomized double-blind clinical trials and a population -based case-control study have generally failed to support these findings [20-22]. In addition, most of the previous studies were explored 25-hydroxyvitamin $\mathrm{D}$, not its active form 1,25-dihydroxycholecalciferol (D3) associated with risk of cancers. We, therefore, performed a case-control analysis using large claim database to assess the association of vitamin D3 intake dose and risk of common site-specific cancer.

\section{Materials and Methods}

\section{Data source}

This was a population-based retrospective case-control study that analyzed data retrieved from the Catastrophic Illness Patient Databases (CIPD) and longitudinal health insurance database (LHID) to identify cases and controls from January 1, 2010 to December 31, 2011and from January 1, 2000 to December 31, 2011, respectively. Both databases are the subset of the National Health Insurance Research Database (NHIRD) and included information of the patient demographics (with encrypted patient identification numbers, birthdates, and sex), inpatient or outpatient claim data, pharmacy records, laboratory and diagnostic test data, dates of visits, lengths of hospitalization, and diagnoses. CIPD is particularly focus on patients diagnosed with catastrophic illness, such as cancer. NHIRD database represents over $99 \%$ of the 23 million inhabitants of Taiwan. We confirm that all data were de-identified and analyzed anonymously.

\section{Cases and controls}

Eligible cases consisted of all patients who were aged 18 years and older and received at least two prescriptions of vitamin D3 and used them continuously for at least 28 days (28 days was the longer duration covered by the NBI bureau) before the index date. The index date was defined as the date that a primary diagnosis was given on any site-specific cancer from January 1, 2010 to December 31, 2011.

Controls were selected by using frequency-match strategy from the LHID from January 1, 2000 to December 31, 2011. For each case, we selected one control without the diagnosis of any site-specific cancer, matched by age, gender under the same inclusion and exclusion criteria as the case. The diagnoses of site-specific cancers in outpatient or inpatient settings were identified from the validated ICD-9-CM codes [23].

\section{Exclusion criteria}

Cases and controls were excluded when they were diagnosed with any cancer during the first year of the study period or they did not receive two prescriptions of vitamin D3 for 28 days.

\section{Primary outcomes}

We determined the risks of most common cancers in Taiwan [24], comparing these for patients used vitamin D3 versus not used vitamin D3. We investigated the following cancers, with the corresponding ICD-9-CM codes: oral cancer (ICD-9-CM 140-149), nasopharngeal cancer (ICD-9-CM 147.xx)gastric cancer (ICD-9-CM 151.xx), colorectal cancer (ICD-9-CM 153-154), hepatic and intrahepatic bile ducts cancer (ICD-9-CM 155), trachea bronchus and lung cancer (ICD-9 162.xx), skin cancer (ICD-9-CM 173.xx), breast cancer (ICD-9-CM 174.xx and 175.xx), endometrial cancer (ICD-9-CM 182), kidney (ICD-9-CM 18.xx) ,bladder cancer (ICD-9-CM 188 and 189.xx), lymphoma and leukemia (ICD-9-CM 200-208) and thyroid (ICD-9-CM 193).

\section{Exposure variables}

Vitamin D3 exposure was defined as all prescriptions for vitamin D3 prescribed at least twice and used continuously for 28 days before the index date (date of first diagnosis of site-specific cancers). The vitamin D3 was identified according to the Anatomical Therapeutic Chemical (ATC) classification system [25-26]. Among the patients that used vitamin D3, the cumulative duration was calculated and categorized as $\leqq 90$ and $\geqq 90$ days. We also calculated the defined daily doses (DDDs) recommended by the WHO [26-27]; the DDDs were used to quantify vitamin D3 use. We adopted the 1-day gap to identify current users or discontinued users, which was further categorized as discontinued use for 1-30 days, 31-365 days and > 365 days. Additionally, the mean daily dose of vitamin D3 prescribed was also categorized as low ( $\leqq 15$ DDD) and high dose (>15 DDD).

\section{Potential covariates}

Potential covariates, previously established as cancer risk factors, were adjusted during multivariate analyses. One covariate was the Charlson comorbidity index used by Deyo et al [28-29]. We also adjusted for co- morbidities present in the 6 months prior to the 
index date, like diabetes mellitus (ICD-9-CM 250.xx), hypertension (ICD-9-CM 401-405.xx), hyperlipidemia (ICD-9-CM 272.xx), sleep disorder (ICD-9-CM 307.xx,327, 780.xx), anxiety (ICD-9-CM 300.xx), depression (ICD-9-CM 296.xx, 311), osteoporosis (ICD-9-CM 733.0, and 733.1), hypoparathyroidism (ICD-9-CM 252.1), spinal cord compression (ICD-9-CM 336.9) and CKD (ICD-9-CM 585.9) , obesity (ICD-9-CM 278) and alcoholism (ICD-9-CM 303). Other covariates were the use of traditional non-steroidal anti-inflammatory drugs, statins, cardiovascular drugs, or hormone-replacement therapy.

\section{Statistical analysis}

Logistic regression was used to estimate the crude and adjusted odds ratio (OR) and 95\% confidence interval (CI) for studied cancer risk. All confounders of interest were included in the model during multivariate analysis. Data was analyzed using SAS version 9.3 (SAS Institute, Cary, NC, USA). The significant level was set at $\mathrm{P}<0.05$ (two-tailed test).

\section{Sensitivity analysis}

We evaluated the robustness of the main results by using several analyses. First, we excluded patients diagnosed with underlying osteoporosis or hypoparathyroidism during follow-up. Second, we restricted the inclusion criteria to include those that received at least two prescriptions of vitamin D3 before the index date. Third, we changed exposure time to vitamin D3 from 28 days to over 90 days and 180 days before the index date.

\section{Results}

According to the inclusion and exclusion criteria, we identified 161805 cancer patients as cases and 161805 non-cancer patients as controls (Figure 1). Table 1 shows the characteristics of the cases and matched controls. No significant differences in mean age and gender $(p=0.21 ; 0.99)$. However, there were significant differences in Charlson co-morbidity index (CCI) score and concomitant use of other medications between the case and control groups ( $\mathrm{p}<0.0001$ ). Table 2 showed significant association between all risk factors and site-specific cancer.

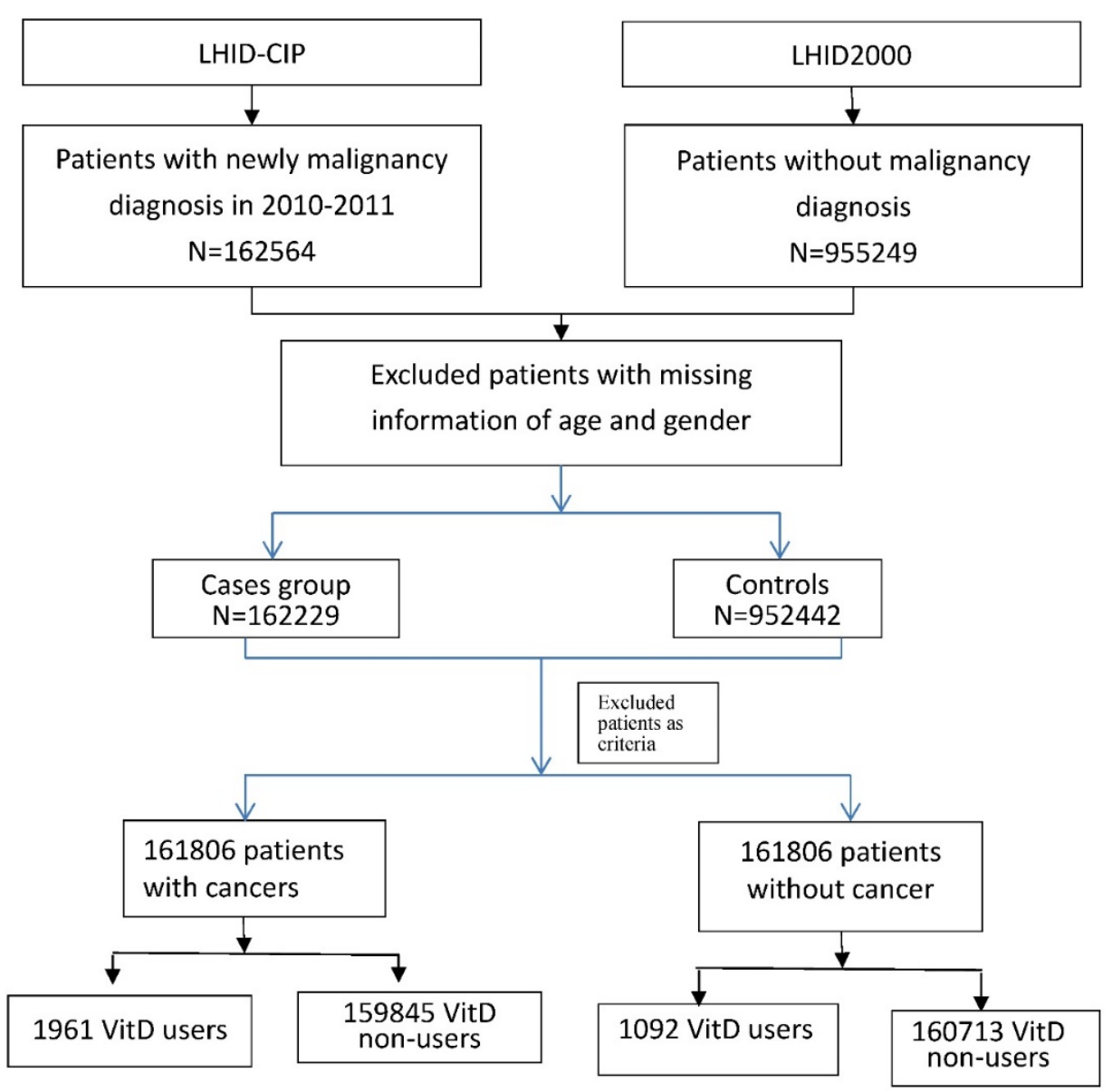

Figure 1. Flow chart showed selection process of study patients. 
Table 3 revealed the prevalence of vitamin D3 and odds ratio for site-specific cancers. There were $1.21 \%(1961 / 161806)$ patients with cancer in cases and $0.67 \%(1092 / 161806)$ patients without cancer in the controls identified were vitamin D3 users. The association between vitamin D3 use with the risk of kidney cancer (OR 2.59; 95\% CI 1.81-3.70) and bladder cancer (OR 4.97; 95\% CI 4.40 -5.60) were statistically significant. However, a slightly inverse significant association between vitamin D 3 users with liver, lung, breast, endometrial, lymphoma and leukemia were observed.

Table 1. Demographic characteristics of patients with cancer versus no cancers.

\begin{tabular}{|c|c|c|c|c|c|}
\hline & \multicolumn{2}{|c|}{$\begin{array}{l}\text { Cancer patients } \\
\quad \mathrm{N}=161805\end{array}$} & \multicolumn{2}{|c|}{$\begin{array}{c}\text { Non-cancer patients } \\
\text { N=161805 }\end{array}$} & \multirow{2}{*}{ p-value } \\
\hline & $\mathrm{n}$ & $\%$ & $\mathrm{n}$ & $\%$ & \\
\hline Age, year & & & & & 0.99 \\
\hline$<50$ & 35338 & 21.8 & 35338 & 21.8 & \\
\hline $50-64$ & 55399 & 34.2 & 55399 & 34.2 & \\
\hline $65+$ & 71068 & 43.9 & 71068 & 43.9 & \\
\hline Mean (SD) & 62.1 & $(15.2)$ & 62.1 & $(15.3)$ & 0.21 \\
\hline Gender & & & & & 0.99 \\
\hline Women & 72715 & 44.9 & 72715 & 44.9 & \\
\hline Men & 89090 & 55.1 & 89090 & 55.1 & \\
\hline CCI score & & & & & $<0.0001$ \\
\hline 0 & 108474 & 67.0 & 122605 & 75.8 & \\
\hline $1-2$ & 41423 & 25.6 & 26085 & 16.1 & \\
\hline $3-4$ & 8639 & 5.34 & 8469 & 5.23 & \\
\hline $5+$ & 3269 & 2.02 & 4646 & 2.87 & \\
\hline Mean (SD) & 0.63 & (1.19) & 0.56 & $(1.31)$ & $<0.0001$ \\
\hline \multicolumn{6}{|l|}{ Comorbidity } \\
\hline Hyperlipidemia & 49281 & 30.5 & 44976 & 27.8 & $<0.0001$ \\
\hline Hypertension & 79590 & 49.2 & 70647 & 43.7 & $<0.0001$ \\
\hline Sleep disorder & 52294 & 32.3 & 43582 & 26.9 & $<0.0001$ \\
\hline Anxiety & 38574 & 23.8 & 33357 & 20.6 & $<0.0001$ \\
\hline Depression & 12351 & 7.63 & 10591 & 6.55 & $<0.0001$ \\
\hline Obesity & 1328 & 0.82 & 1036 & 0.64 & $<0.0001$ \\
\hline Alcoholism & 5111 & 3.16 & 2546 & 1.57 & $<0.0001$ \\
\hline \multicolumn{6}{|l|}{ Medicine } \\
\hline CV drug & 85006 & 32.1 & 37988 & 23.5 & $<0.0001$ \\
\hline Estrogen & 453 & 0.28 & 295 & 0.18 & $<0.0001$ \\
\hline Statin & 21446 & 13.3 & 17421 & 10.8 & $<0.0001$ \\
\hline NSAID & 108419 & 67.0 & 72454 & 44.8 & $<0.0001$ \\
\hline Vitamin D & 1961 & 1.21 & 1092 & 0.67 & $<0.0001$ \\
\hline
\end{tabular}

Table 4 presented stratification data on the total number of vitamin D3 users and non-users, including dose-response, exposure duration and daily DDD of vitamin D3. The risk of bladder cancers was statistically increased as the mean daily DDD of vitamin D3 over 15 . Other site specific cancers were statistically insignificant with the increase of vitamin D3 intake dose over 15 DDD.

In sensitivity analysis, the main results were robust by using several analyses. The odds ratio of kidney cancer and bladder cancer were similar to the main results and robust in the sensitivity analysis (Figure 2).

Table 2. Risk factors for site-specific cancers.

\begin{tabular}{|c|c|c|}
\hline & Crude OR $(95 \%$ CI) & Adjusted OR $(95 \% \mathrm{CI})$ \\
\hline \multicolumn{3}{|l|}{ Vitamin D } \\
\hline No & 1.00 & 1.00 \\
\hline Yes & $1.71(1.52-1.92)^{* * *}$ & $1.51(1.34-1.70)^{\star * *}$ \\
\hline \multicolumn{3}{|l|}{ Age, year } \\
\hline$<50$ & 1.00 & 1.00 \\
\hline $50-64$ & $1.00(0.98-1.02)$ & $0.92(0.91-0.94)^{* * *}$ \\
\hline $65+$ & $1.00(0.98-1.02)$ & $0.87(0.85-0.89)^{* * *}$ \\
\hline \multicolumn{3}{|l|}{ Gender } \\
\hline Women & 1.00 & 1.00 \\
\hline Men & $1.00(0.99-1.01)$ & $1.04(1.02-1.05)^{\star * *}$ \\
\hline \multicolumn{3}{|l|}{ CCI score } \\
\hline 0 & 1.00 & 1.00 \\
\hline $1-2$ & $1.80(1.76-1.83)^{\star * *}$ & $1.80(1.76-1.83)^{\star \star \star *}$ \\
\hline $3-4$ & $1.15(1.12-1.19)^{* * *}$ & $1.25(1.21-1.29)^{\star \star *}$ \\
\hline $5+$ & $0.80(0.76-0.83)^{\star * *}$ & $0.94(0.89-0.99)^{*}$ \\
\hline \multicolumn{3}{|l|}{ Comorbidity } \\
\hline Hyperlipidemia & $1.14(1.12-1.16)^{\star * *}$ & $0.90(0.88-0.91)^{\star \star \star *}$ \\
\hline Hypertension & $1.25(1.23-1.27)^{* * *}$ & $0.99(0.97-1.01)$ \\
\hline Sleep disorder & $1.30(1.28-1.32)^{* * *}$ & $1.10(1.08-1.11)^{\star * *}$ \\
\hline Anxiety & $1.21(1.19-1.23)^{* * *}$ & $0.98(0.96-0.99)^{*}$ \\
\hline Depression & $1.18(1.15-1.21)^{* * *}$ & $0.99(0.96-1.02)$ \\
\hline Obesity & $1.28(1.18-1.39)^{* * *}$ & $1.08(0.99-1.18)$ \\
\hline Alcoholism & $2.04(1.94-2.14)^{* * *}$ & $1.88(1.79-1.98)^{\star * *}$ \\
\hline \multicolumn{3}{|l|}{ Medicine } \\
\hline CV drug & $1.54(1.52-1.56)^{* * *}$ & $1.39(1.36-1.42)^{* * *}$ \\
\hline Estrogen & $1.54(1.33-1.78)^{* * *}$ & $1.35(1.16-1.57)^{\star * *}$ \\
\hline Statin & $1.27(1.24-1.29)^{* * *}$ & $1.06(1.03-1.09)^{\star * *}$ \\
\hline NSAID & $2.50(2.47-2.54)^{* * *}$ & $2.43(2.39-2.47)^{\star * *}$ \\
\hline
\end{tabular}

${ }^{*} \mathrm{p}<0.05,{ }^{* *} \mathrm{p}<0.01,{ }^{* * *} \mathrm{p}<0.001$

Chi-square and t-test.

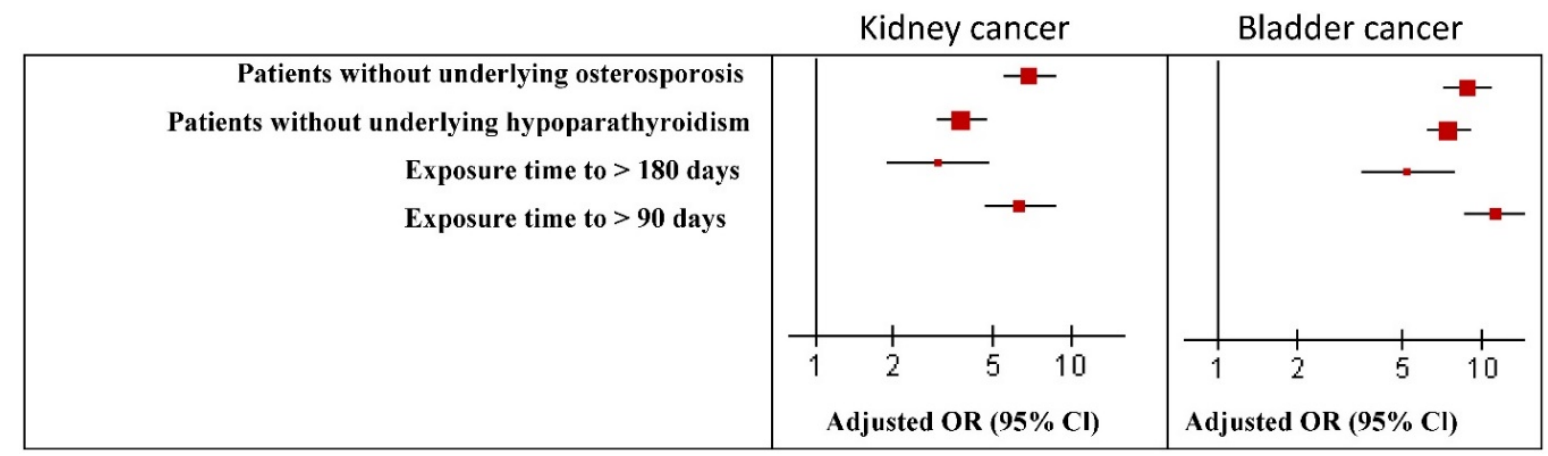

Figure 2. Risk of kidney and bladder cancer associated with Vitamin D user and non-user in the sensitivity analyses. $* P<0.05$. OR, Odds ratio; $C l$, confidence interval. 
Table 3. Odds ratio for site-specific cancers between vitamin $D$ users versus vitamin $D$ non-users.

\begin{tabular}{|c|c|c|c|c|c|c|}
\hline \multirow[b]{2}{*}{ Type (ICD-9-CM) } & \multicolumn{2}{|c|}{ Cancer group } & \multicolumn{2}{|c|}{ Non-cancer group } & \multicolumn{2}{|l|}{ OR $(95 \% \mathrm{CI})$} \\
\hline & $\begin{array}{l}\text { Vitamin D } \\
\text { users (no.) }\end{array}$ & $\%$ & $\begin{array}{l}\text { Vitamin D } \\
\text { users (no.) }\end{array}$ & $\%$ & Univariate model & Multivariate model \\
\hline All cancer & 1961 & 1.21 & 1092 & 0.67 & $1.81(1.68-1.95)^{* * *}$ & $1.67(1.55-1.81)^{* * *}$ \\
\hline Oral $(140,142-145,149)$ & 21 & 0.34 & 3032 & 0.96 & $0.35(0.23-0.54)^{\star * *}$ & $0.64(0.41-1.00)$ \\
\hline NPC (147) & 12 & 0.40 & 3041 & 0.95 & $0.42(0.24-0.74)^{\star *}$ & $0.74(0.42-1.32)$ \\
\hline Stomach (151) & 59 & 0.90 & 2994 & 0.94 & $0.95(0.73-1.23)$ & $0.85(0.66-1.11)$ \\
\hline Colorectal (153-154) & 200 & 0.84 & 2853 & 0.95 & $0.88(0.77-1.02)$ & $0.90(0.78-1.04)$ \\
\hline Liver (155) & 217 & 1.10 & 2836 & 0.93 & $1.18(1.03-1.36)^{*}$ & $0.70(0.60-0.81)^{* * *}$ \\
\hline Lung (162) & 134 & 0.74 & 2919 & 0.96 & $0.78(0.65-0.92)^{* *}$ & $0.74(0.62-0.88)^{* * *}$ \\
\hline Skin (173) & 29 & 1.08 & 3024 & 0.94 & $1.14(0.79-1.65)$ & $0.99(0.68-1.43)$ \\
\hline Female breast (174) & 114 & 5.97 & 19125 & 13.3 & $0.41(0.34-0.50)^{* * * *}$ & $0.58(0.47-0.70)^{* * *}$ \\
\hline Female endometrial (182) & 14 & 0.73 & 2880 & 2.01 & $0.36(0.21-0.61)^{* * *}$ & $0.48(0.28-0.81)^{\star *}$ \\
\hline Male prostate (185) & 53 & 4.63 & 8190 & 4.63 & $1.00(0.76-1.32)$ & $1.07(0.81-1.43)$ \\
\hline Kidney (189.0 and 198.0) & 33 & 2.57 & 3020 & 0.94 & $2.79(1.97-3.95)^{* * *}$ & $2.59(1.81-3.70)^{* * *}$ \\
\hline Bladder $(188,189.1-189.9)$ & 334 & 4.35 & 2719 & 0.86 & $5.24(4.66-5.88)^{* * * *}$ & $4.97(4.40-5.60)^{* * *}$ \\
\hline Lymphoma and leukemia (200-208) & 52 & 1.70 & 7609 & 2.37 & $0.71(0.54-0.94)^{*}$ & $0.67(0.51-0.88)^{* *}$ \\
\hline Others & 689 & 1.98 & 2364 & 0.82 & $2.45(2.25-2.67)^{* * *}$ & $2.45(2.25-2.67)^{* * *}$ \\
\hline
\end{tabular}

Adjusted for age, gender, CCI score and comorbidity, no: number of patients.

Rate, per 1000 person-years.

${ }^{* *} \mathrm{p}<0.01,{ }^{* * *} \mathrm{p}<0.001$.

Table 4. Stratification analysis on Vitamin D user versus non-users associated with site-specific cancers.

\begin{tabular}{|c|c|c|c|c|c|c|c|c|c|}
\hline & \multicolumn{3}{|c|}{ All cancer } & \multicolumn{3}{|l|}{ Liver } & \multicolumn{3}{|l|}{ Lung } \\
\hline & $\begin{array}{l}\text { Cancer } \\
\text { patient }\end{array}$ & $\begin{array}{l}\text { Non } \\
\text { Cancer } \\
\text { patient }\end{array}$ & OR $(95 \% \mathrm{CI})$ & $\begin{array}{l}\text { Cancer } \\
\text { patient }\end{array}$ & $\begin{array}{l}\text { Non } \\
\text { Cancer } \\
\text { patient }\end{array}$ & OR $(95 \% \mathrm{CI})$ & $\begin{array}{l}\text { Cancer } \\
\text { patient }\end{array}$ & $\begin{array}{l}\text { Non } \\
\text { Cancer } \\
\text { patient }\end{array}$ & OR $(95 \% \mathrm{CI})$ \\
\hline Vitamin D nonusers & 159844 & 160713 & 1.00 & 19489 & 301068 & 1.00 & & & 1.00 \\
\hline \multicolumn{10}{|l|}{ Vitamin D users } \\
\hline \multicolumn{10}{|l|}{ Discontinued used } \\
\hline 1-30 days & 584 & 37 & $15.2(10.9-21.3)^{* * *}$ & 8 & 613 & $0.20(0.10-0.40)^{* * *}$ & 13 & 608 & $0.46(0.27-0.80)^{* *}$ \\
\hline 31-365 days & 1100 & 917 & $1.10(1.01-1.21)^{*}$ & 176 & 1841 & $0.81(0.69-0.95)^{*}$ & 104 & 1913 & $0.80(0.65-0.97)^{*}$ \\
\hline$>365$ days & 277 & 138 & $1.81(1.47-2.24)^{* * *}$ & 33 & 382 & $0.66(0.45-0.95)^{*}$ & 17 & 398 & $0.77(0.47-1.25)$ \\
\hline \multicolumn{10}{|l|}{ Daily DDD } \\
\hline$<=15$ & 1958 & 1090 & $1.67(1.55-1.81)^{* * *}$ & 217 & 2831 & $0.70(0.61-0.81)^{* * *}$ & 134 & 2914 & $0.74(0.62-0.88)^{* * *}$ \\
\hline$>15$ & 3 & 2 & $0.97(0.16-6.00)$ & 0 & 5 & NA & 0 & 5 & NA \\
\hline \multicolumn{10}{|l|}{ Continuous use } \\
\hline Short-term use ( $<=90$ days) & 1387 & 767 & $1.70(1.56-1.87)^{\star * *}$ & 141 & 2013 & $0.68(0.57-0.81)^{* * *}$ & 87 & 2067 & $0.68(0.55-0.84)^{* * *}$ \\
\hline \multirow[t]{2}{*}{ Long-term use (> 90 days) } & 574 & 325 & $1.60(1.39-1.84)^{* * *}$ & 76 & 823 & $0.74(0.58-0.94)^{*}$ & 47 & 852 & $0.89(0.66-1.20)$ \\
\hline & \multicolumn{3}{|l|}{ Kidney } & \multicolumn{3}{|c|}{ Bladder } & \multicolumn{3}{|c|}{ Lymphoma and leukemia } \\
\hline Vitamin D nonusers & 1250 & 319307 & 1.00 & 7349 & 313208 & 1.00 & 7609 & 312948 & 1.00 \\
\hline \multicolumn{10}{|l|}{ Vitamin D users } \\
\hline \multicolumn{10}{|l|}{ Discontinued used } \\
\hline 1-30 days & 4 & 617 & $1.56(0.58-4.19)$ & 20 & 601 & $1.90(1.21-2.98)^{* *}$ & 13 & 608 & $0.71(0.41-1.23)$ \\
\hline 31-365 days & 22 & 1995 & $2.68(1.73-4.13)^{* * *}$ & 224 & 1793 & $4.59(3.96-5.30)^{* * *}$ & 36 & 1981 & $0.79(0.57-1.10)$ \\
\hline$>365$ days & 7 & 408 & $3.69(1.73-7.90)^{* * *}$ & 90 & 325 & $12.2(9.58-15.6)^{\star * *}$ & 3 & 412 & $0.28(0.09-0.88)^{*}$ \\
\hline \multicolumn{10}{|l|}{ Daily DDD } \\
\hline$<=15$ & 33 & 3015 & $2.60(1.82-3.71)^{\star * *}$ & 333 & 2715 & $4.96(4.39-5.60)^{* * *}$ & 52 & 2996 & $0.70(0.53-0.92)^{*}$ \\
\hline$>15$ & 0 & 5 & NA & 1 & 4 & $9.04(1.00-82.6)^{*}$ & 0 & 5 & NA \\
\hline \multicolumn{10}{|l|}{ Continuous use } \\
\hline Short-term use $(<=90$ days) & 18 & 2136 & $2.07(1.29-3.33)^{\star * *}$ & 166 & 1988 & $3.42(2.90-4.03)^{* * *}$ & 42 & 2112 & $0.80(0.59-1.09)$ \\
\hline \multirow[t]{2}{*}{ Long-term use (> 90 days) } & 15 & 884 & $3.73(2.21-6.30)^{* * *}$ & 168 & 731 & $9.09(7.62-10.8)^{\star * *}$ & 10 & 889 & $0.45(0.24-0.84)^{*}$ \\
\hline & \multicolumn{3}{|l|}{ Other } & \multicolumn{3}{|c|}{ Female breast } & \multicolumn{3}{|c|}{ Female endometrial } \\
\hline Vitamin D nonusers & 194812 & 125745 & & 19125 & 124396 & & 2894 & 142536 & \\
\hline \multicolumn{10}{|l|}{ Discontinued used } \\
\hline 1-30 days & 518 & 103 & $3.38(2.73-4.19)^{* * *}$ & 9 & 448 & $0.09(0.05-0.18)^{* * *}$ & 1 & 456 & $0.08(0.01-0.59)^{*}$ \\
\hline 31-365 days & 1084 & 933 & $0.89(0.81-0.97)^{*}$ & 78 & 1120 & $0.88(0.69-1.11)$ & 8 & 1190 & $0.56(0.28-1.14)$ \\
\hline$>365$ days & 179 & 236 & $0.57(0.46-0.69)^{* * *}$ & 27 & 227 & $1.56(1.04-2.35)^{*}$ & 5 & 249 & $1.72(0.70-4.21)$ \\
\hline \multicolumn{10}{|l|}{ Daily DDD } \\
\hline$<=15$ & 1778 & 1270 & $1.04(0.97-1.13)$ & 114 & 1792 & $0.58(0.47-0.70)^{* * *}$ & 14 & 1892 & $0.48(0.28-0.81)^{* *}$ \\
\hline$>15$ & 3 & 2 & $1.48(0.24-9.07)$ & 0 & 3 & NA & 0 & 3 & NA \\
\hline \multicolumn{10}{|l|}{ Continuous use } \\
\hline Short-term use (<= 90 days) & 1381 & 773 & $1.32(1.21-1.45)^{* * * *}$ & 72 & 1304 & $0.45(0.36-0.58)^{* * *}$ & 8 & 1368 & $0.35(0.18-0.71)^{* *}$ \\
\hline Long-term use (> 90 days) & 400 & 499 & $0.61(0.53-0.70)^{* * *}$ & 42 & 491 & $1.05(0.76-1.45)$ & 6 & 527 & $0.92(0.41-2.07)$ \\
\hline
\end{tabular}

${ }^{*} \mathrm{p}<0.05,{ }^{* *} \mathrm{p}<0.01,{ }^{* * *} \mathrm{p}<0.001$. 


\section{Discussion}

Our finding revealed a statistically significant risk of bladder cancer associated with vitamin D3 intake of mean daily dose $\leqq 15$ DDD in a population retrieved from large claim database, in which the use of vitamin D3 was restricted to patients who have vitamin $\mathrm{D}$ dependent rickets or hypophosphatemia rickets, hypoparathyroidism and hypocalcemia caused by chronic renal insufficiency. However, the association between vitamin D3 intake dose >15 DDD and bladder cancer risk was statistical significant. This finding is likely inconsistent with other previous studies which observed that high dose of vitamin D3 may reduce risk of bladder cancer. The reason may be due to the fact that the patients with underline disease of hypophosphatemia rickets need to take high dose of phosphorus. Since the high intakes of calcium and phosphorus may down regulated the active form of vitamin D3 levels in our body and therefore increased risk of bladder cancer [30-34]. Except this, our finding was consistent with most epidemiological studies and meta-analysis published in recent 5 years reported that the association between vitamin $\mathrm{D}$ intake and cancer risk was not significant $[8,9,22,25,35]$.

A meta-analysis on vitamin D3 intake and breast cancer by Chen and colleagues found a statistically significant lower risk of breast cancer for women in high vitamin $\mathrm{D}$ intake dose of 1000 i.u./day (equivalent to 25 DDD) [36]. In comparison, we found a significant inverse association between breast cancer and vitamin D3 intake dose of $15 \mathrm{DDD}$, the result seems to be consistent (OR 0.58; 95\% CI $0.47-0.70$ ).

Our results for prostate cancer and vitamin D3 intake is also in line with the studies collected in a meta-analysis, which revealed that the odds ratio of prostate cancer for patients, who have increased per 1000 i.u.(> $25 \mathrm{ug})$ vitamin D dietary intake was 1.14 (95\% CI 0.99-1.31) [37]. In comparison, ours was 1.07 (95\% CI 0.81-1.43). Therefore, it is likely an evidence to support a role of vitamin $\mathrm{D}$ in preventing prostate cancer.

A meta-analysis on vitamin D and colorectal cancer by $\mathrm{Ma}$ and colleagues showed an inverse association between high intakes of vitamin $\mathrm{D}$ dose over 600i.u./day (15 DDD/day) [11]. In comparison, we found borderline significant inverse associations between mean daily dose of vitamin D3 of 15DDD (OR 0.90, 95\% CI 0.78-1.04).

For gastric cancer, a meta-analysis of seven articles published recently also indicated that no significant association between vitamin $\mathrm{D}$ intake and risk of gastric cancer (OR:1.09, 95\% CI 0.94-1.25) versus our OR was 0.85 (0.66-1.11) [38].

The strengths of our study would be worth revealed commendable. First we collected information from a large population-based database that included health care beneficiaries who were registered prospectively with complete data on drug prescriptions and cancer diagnoses. Thus, the possibility of selection and information biases was minimized. Second, the accuracy of ICD-9 coding for cancers was based on pathology finding and validated by cancer-registry system in Taiwan. Third, only activated vitamin D3 was covered by the insurance program which may minimize any bias resulting from non-differential misclassification of vitamin $\mathrm{D}$. Forth, the different methods of measuring vitamin $\mathrm{D}$ dose caused residual confounding bias might be minimized. However, there were also some limitations to our study. First, the health insurance database that we used was developed for administrative purposes. It contained de-identified records of individuals, including physicians, hospitals, personal care homes, home care, and pharmaceutical prescriptions, it required substantial effort to convert it into a research database from which information could be retrieved. Second, the database did not contain information on certain risk factors of cancer, like the level of physical activity, alcohol consumption, smoking, socioeconomic status, diet, and information on cancer screening tests (mammography, prostate-specific antigen test, or colonoscopy); therefore, these were not included in the analysis, some residual confounding may be existed. Third, we adjusted the risk of cancer for possible effects of co-morbidities and the use of other medications, but the possibility of misclassification of those variables might bias our results. Fourth, we can only identify vitamin D3 from the claim database because of the coverage policy, the bias may be considered in different serum concentrations of 25-hydroxyvitamin D and vitamin D3. However, the pharmacokinetic study proved that vitamin D2 and D3 were equally effective in elevating 25OHD levels after a loading dose because the dose of vitamin D3 is the dominant factor to change in serum 25-hydroxyvitamin D [39], therefore, we assumed the effect of vitamin D3 on serum 25-hydroxyvitamin D in our study was same as the effect of D2 on serum 25-hydroxyvitamin D assessed in other studies.

In conclusion, except bladder cancer in stratification analysis, we observed no statistically significant associations between high intake of vitamin D3 and other site-specific cancers.

\section{Acknowledgments}

We acknowledge with thanks the Taiwan Ministry of Health and Welfare Clinical Trial and Research Center of Excellence (MOHW104-TDU-B- 
212-113002), China Medical University Hos-pital, Academia Sinica Taiwan Biobank Stroke Biosignature Project (BM104010092), NRPB Stroke Clinical Trial Consortium (MOST 103-2325-B-039-006), Tseng-Lien Lin Foundation, Taichung, Taiwan, Taiwan Brain Disease Foundation, Taipei, Taiwan, and Katsuzo and Kiyo Aoshima Memorial Funds, Japan for their contribution.

\section{Author's Contributions}

Conception and design: Agnes Chan, Henry W.C. Leung. Development of methodology: Agnes Chan. Analysis and interpretation data (e.g. statistical analysis): Chih-Hsin Mou, Chung-Feng Liu. Writing, review, and/or revision of the manuscript: Agnes Chan.

\section{Competing Interests}

The authors have declared that no competing interest exists.

\section{References}

1. [Internet] World Health Organization. http://www.who.int/mediacentre/ factsheets/fs297/en/

2. [Internet] Taiwan Cancer Registry. http://tcr.cph.ntu.edu.tw/ main.php?Page $=\mathrm{N} 2$.

3. Parsa N. Environmental factors inducing human cancers. Iran J Public 2012;41(11):1-9.

4. Ness RA, Miller DD, Li W. The role of vitamin D in cancer prevention. Chin J Nat Med. 2015;13(7):481-97.

5. Holick MF. High prevalence of vitamin D inadequacy and implications for health. Mayo Clin Proc. $2006 ; 81(3): 353-73$.

6. Mantel DJ Owens PE Bundred NJ, Mawer EB, Canfield AE 1a, 25-dihydroxyvitamin D3 inhibits angiogenesis in vitro and in vivo. Circ Res 2000;87:214-220

7. Holick MF. Vitamin D deficiency. N Engl J Med. 2007;357(3):266-81.

8. Bikle DD. Vitamin D and cancer: the promise not yet fulfilled. Endocrine. $2014 ; 46(1): 29-38$.

9. Abbas S, Linseisen J, Rohrmann S, et al. Dietary intake of vitamin d and calcium and breast cancer risk in the European prospective investigation into cancer and nutrition. Nutr Cancer 2013;65(2): 178-187.

10. Rossi M, McLaughlin JK, Lagiou P, et al. Vitamin D intake and breast cancer risk: a case-control study in Italy. Ann Oncol 2009:20(2):374-8.

11. Ma Y, Zhang P, Wang F, et al. Association between vitamin D and risk of colorectal cancer: a systematic review of prospective studies. J Clin Oncol 2011 29(28):3775-82

12. Ben Fradj MK, Gargouri MM, Hammami MB, et al. Bladder cancer is associated with low plasma 25-hydroxyvitamin D concentrations in Tunisian population. Nutr Cancer. 2016;68(2):208-13

13. Chen P, Li M, Gu X, et al. Higher blood 25(OH)D level may reduce the breast cancer risk: evidence from a Chinese population based case-control study and meta-analysis of the observational studies. PLoS One. 2013;8(1):e49312

14. Bilinski K, Boyages J. Association between 25-hydroxyvitamin D concentration and breast cancer risk in an Australian population: an observational case-control study. Breast Cancer Res Treat. 2013 ;137(2):599-607

15. Gandini S, Boniol M, Haukka J, et al. Meta-analysis of observational studies of serum 25-hydroxyvitamin D levels and colorectal, breast and prostate cancer and colorectal adenoma. Int J Cancer. 2011 ;128(6):1414-24

16. Kim Y, Franke AA, Shvetsov YB, et al. Plasma 25-hydroxyvitamin D3 is associated with decreased risk of postmenopausal breast cancer in whites: a nested case-control study in the multiethnic cohort study. BMC Cancer. 2014;14:29.

17. Woolcott CG, Wilkens LR, Nomura AM, et al. Plasma 25-hydroxyvitamin D levels and the risk of colorectal cancer: the multiethnic cohort study. Cancer Epidemiol Biomarkers Prev. 2010;19(1):130-4

18. Park SY, Cooney RV, Wilkens LR, et al. Plasma 25-hydroxyvitamin D and prostate cancer risk: the multiethnic cohort. Eur J Cancer. 2010;46(5):932-6.

19. Joh HK, Giovannucci EL, Bertrand KA, et al. Predicted plasma 25-hydroxyvitamin D and risk of renal cell cancer. J Natl Cancer Inst. 2013;105(10):726-32

20. Ahn HY, Chung YJ, Park KY, et al. Serum 25-Hydroxyvitamin D Level Does Not Affect the Aggressiveness and Prognosis of Papillary Thyroid Cancer. Thyroid. 2016;26(3):429-33
21. Kelly JL, Salles G, Goldman B, et al. Low Serum Vitamin D Levels Are Associated With Inferior Survival in Follicular Lymphoma: A Prospective Evaluation in SWOG and LYSA Studies. J Clin Oncol. 2015 ;33(13):1482-90.

22. Jacobs ET, Kohler LN, Kunihiro AG, et al. Vitamin D and Colorectal, Breast, and Prostate Cancers: A Review of the Epidemiological Evidence. J of Cancer. 2016 ;7(3):232-40

23. [Internet] National Health Insurance Administration Ministry of Health and Welfare. http://www.nhi.gov.tw/Resource/webdata/Attach_3469_2 _ICD2001-\%E6\%9B\%B4\%E6\%96\%B0\%E7\%89\%88.pdf

24. [Internet] Taiwan Cancer Registry. http://www.mc.ntu.edu.tw/CRS/main. php?Page=N2

25. [Internet] Application of ATC code. http://www.whocc.no/atc/application_ for_atc_codes/

26. [Internet] WHO Collaborating Centre for Drug Statistics Methodology:ATC/DDD Index 2016. http://www.whocc.no/atc_ddd_ index/

27. Charlson ME, Pompei $\mathrm{P}$, Ales $\mathrm{KL}$, et al. A new method of classifying prognostic comorbidity in longitudinal studies: development and validation. J Chronic Dis 1987;40:373-83.

28. Deyo RA, Cherkin DC, Ciol MA. Adapting a clinical comorbidity index for use with ICD-9-CM administrative databases. J Clin Epidemiol 1992;45:613-19

29. Leung HW, Chan AL, Lo D, Leung JH, Chen HL. Common cancer risk and statins: a population-based case-control study in a Chinese population. Expert Opin Drug Saf. 2013;12(1):19-27.

30. Brinkman MT, Buntinx F, Kellen E, Dagnelie PC, Van Dongen MC, Muls E, Zeegers MP. Dietary intake of micronutrients and the risk of developing bladder cancer: results from the Belgian case-control study on bladder cancer risk. Cancer Causes Control. 2011;22(3):469-78.

31. Zhao Y, Chen C, Pan W, et al. Comparative efficacy of vitamin D status in reducing the risk of bladder cancer: A systematic review and network meta-analysis. Nutrition. $2016 ; 32(5): 515-23$.

32. Zhang $\mathrm{H}$, Zhang $\mathrm{H}$, Wen $\mathrm{X}$, et al. Vitamin D Deficiency and Increased Risk of Bladder Carcinoma: A Meta-Analysis. Cell Physiol Biochem. 2015;37(5):1686-92.

33. Peiris AN, Bailey BA, Manning T. Relationship of vitamin D monitoring and status to bladder cancer survival in veterans. South Med J. 2013 ;106(2):126-30.

34. Liao Y, Liao Y, Huang JL, Qiu MX, et al. Impact of serum vitamin D level on risk of bladder cancer: a systemic review and meta-analysis. Tumour Biol 2015; 36(3):1567-72

35. Ahmad II, Trikudanathan G, Feinn R et al. Low Serum Vitamin D: A Surrogate Marker for Advanced Colon Adenoma? J Clin Gastroenterol 2016;50(8):644-8.

36. Chen $\mathrm{P}, \mathrm{Hu} \mathrm{P}, \mathrm{Xie} \mathrm{D}$, et al. Meta-analysis of vitamin $\mathrm{D}$, calcium and the prevention of breast cancer. Breast Cancer Res Treat. $2010 ; 121(2): 469-77$.

37. Gilbert R, Martin RM, Beynon R, et al. Associations of circulating and dietary vitamin $\mathrm{D}$ with prostate cancer risk: a systematic review and dose-response meta-analysis. Cancer Causes Control. $2011 ; 22(3): 319-40$

38. Khayatzadeh S, Feizi A, Saneei P, et al. Vitamin D intake, serum Vitamin D levels, and risk of gastric cancer: A systematic review and meta-analysis. J Res Med Sci. 20(8):790-6, 2015.

39. Oliveri B, Mastaglia SR, Brito GM, et al. Vitamin D3 seems more appropriate than D2 to sustain adequate levels of 25OHD: a pharmacokinetic approach. Eur J Clin Nutr. $2015 ; 69(6): 697-702$ 